Revista Destaques Acadêmicos, Lajeado, v. 12, n. 1, 2020. ISSN 2176-3070

DOI: http://dx.doi.org/10.22410/issn.2176-3070.v12i1a2020.2485

http://www.univates.br/revistas

\title{
DESLOCAMENTO PENDULAR DE ESTUDANTES PROMOVIDO PELA UNIVERSIDADE DO VALE DO TAQUARI - UNIVATES
}

\author{
Bernardete Bregolin Cerutti ${ }^{1}$, Gabriel Machado Braido ${ }^{2}$
}

Resumo: Este estudo busca identificar o deslocamento pendular de estudantes promovido pela Universidade do Vale do Taquari - Univates. Para alcançar este objetivo, realizou-se uma pesquisa com abordagem quali-quantitativa, por meio de levantamento de dados secundários em fontes bibliográficas e documentais, e pela medição e análise numérica. Os resultados demonstram que a universidade apresenta um crescente dinamismo, o que tem provocado a atração de pessoas para estudar, além de promover a desconcentração metropolitana e o desenvolvimento regional.

Palavras-chave: Deslocamento pendular. Universidade do Vale do Taquari. Univates. Mobilidade.

\section{INTRODUÇÃO}

O espaço urbano contemporâneo mostra-se complexo, caracterizado por processos de mudança rápidos e profundos que têm gerado novas formas e configurações espaciais, novos ritmos de vida, novos valores, novos relacionamentos entre pessoas e organizações e novos processos produtivos em escala mundial.

Nesse espaço, os grupos sociais se articulam e determinam o local para habitar, trabalhar e estudar, em meio a diferentes estratégias e necessidades, gerando movimentos de ir e vir, denominados de "deslocamento pendular", que significa um tipo de mobilidade populacional intraurbana, mais intenso em áreas de maior concentração populacional, tornando-se um importante aspecto a ser considerado na dinâmica urbana.

1 Doutoranda em Desenvolvimento Regional (UNISC). Mestre em Ambiente e Desenvolvimento (Univates). Professora assistente da Universidade do Vale do Taquari - Univates. E-mail: bcerutti@univates.br

2 Doutor em Administração (Unisinos). Professor Adjunto da Universidade do Vale do Taquari - Univates. E-mail: gabrielb@univates.br 
A natureza dos deslocamentos pendulares difere da compreendida pelos movimentos migratórios, embora implique fluxos de pessoas no território. No deslocamento pendular, entende-se que a dinâmica envolve um deslocamento diário e não uma transferência definitiva, ou por tempo indeterminado, para outro lugar.

Entre cidades que se situam muito próximas, é comum perceber relações tão intensas que certos fluxos, como de pessoas, produção, mercadorias e ideias passam a se entrelaçar em um processo de complementaridade de papéis e funções. É o caso da região do Vale do Taquari-RS, formada por 36 municípios, em uma área de $4.826,7 \mathrm{~km}^{2}$, onde vivem 348.435 habitantes.

A integração entre os municípios, a diversificação econômica e suas riquezas cultural e social oriundas das diversas etnias que participaram de sua formação caracterizam o Vale do Taquari como um local de muitas possibilidades, onde a população vive em harmonia e busca o seu desenvolvimento com trabalho e dedicação.

Nesta região encontra-se Lajeado, emancipada em 1891 e elevada à categoria de cidade em 1939, tornou-se a maior em número de habitantes, com 71.445 , e uma das menores em área territorial, $90,4 \mathrm{~km}^{2}(1,87 \%$ da área territorial do Vale), fazendo com que a densidade demográfica, em 2010, conforme Censo do IBGE, atingisse mais de $790 \mathrm{hab} / \mathrm{km}^{2}$, ocupando a $11^{\mathrm{a}}$ posição no ranking dos 496 municípios gaúchos. Tais dados demonstram a concentração da população na sede municipal, ou seja, no território urbano.

Ao completar 126 anos de emancipação, com essa concentração populacional urbana, Lajeado destaca-se pela diversidade econômica nas áreas comercial, industrial e de prestação de serviços. Integra-se a este cenário a Universidade do Vale do Taquari - Univates, uma instituição com mais de 10 mil estudantes, oriundos de diferentes cidades, que ajudam a impulsionar projetos no cenário econômico, tecnológico e social do município e de toda a região.

Nessas condições, o uso da informação de deslocamento pendular como objeto de estudo é uma importante ferramenta para entender as relações de circularidade de pessoas em uma determinada cidade e região. Sendo assim, o objetivo desta pesquisa é identificar o deslocamento pendular de estudantes promovido pela Universidade do Vale do Taquari - Univates.

Em termos metodológicos, este estudo classifica-se como uma pesquisa de abordagem mista, tendo sua com abordagem qualitativa realizada a partir de dados secundários em fontes bibliográficas que apresentam convergência com o tema pesquisado e em fontes documentais disponibilizadas pela universidade e a sua abordagem quantitativa por agregar medição e análise numérica, por meio de tabelas de percentuais.

A fim de ordenar as ideias, organizou-se sete seções: além desta introdutória, que permite situar o leitor sobre o tema, na segunda seção, é 
apresentada uma breve contextualização sobre cidade, região e pendularidade; na terceira seção, a rede urbana e a cidade-região; na quarta, a região do Vale do Taquari-RS; na quinta seção, a Universidade do Vale do Taquari - Univates; e na sexta, os resultados da pesquisa. Já na sétima seção, estão as considerações finais.

\section{CIDADE, REGIÃO E PENDULARIDADE: RELAÇÕES QUE SE ENTRELAÇAM}

O conceito de cidade é complexo e contraditório entre os especialistas (SOUZA, 2008), entretanto, o que se deseja aqui é buscar uma aproximação, possivelmente com uma dose de generalização, visando a compreender as relações que se entrelaçam entre as cidades e as regiões.

Na tentativa dessa aproximação conceitual, procurando o que há de comum entre as concepções dos especialistas, destaca-se que a cidade é uma área urbanizada que se diferencia por apresentar características atreladas à densidade populacional, ao sedentarismo como movimento inverso ao nomadismo, ao estatuto legal, à economia de produção não agrícola, à troca de mercadorias e à administração pública. (LENCIONI, 2008).

Assim, toda cidade é vista em uma perspectiva espacial, com atividades econômicas de maior ou menor nível, de acordo com a sua centralidade, ou seja, de acordo com a quantidade e diversidade de bens e/ou serviços que oferta, fazendo com que atraia consumidores das cidades do seu entorno ou de toda uma região, país ou países, conforme o grau de sofisticação desses bens produzidos e/ou serviços prestados. (CARLOS, 2000).

Dessa forma, a cidade aparece como materialidade, produto do processo de trabalho, de sua divisão técnica e social, normatizada por ideologias na forma de pensar, sentir e consumir, logo, de um modo de vida que produz ideias, comportamentos, valores, conhecimentos e, também, história e cultura.

A história e a cultura desempenham papel relevante na projeção de uma cidade, que vai além de seus limites físicos, assim como o poder. A cidade é um centro de gestão do território não apenas como sede de empresas públicas, privadas e estatais, mas também enquanto sede do poder religioso e político. Por isso, é um local onde pessoas trabalham, se organizam e interagem com base em diferentes interesses, afinidades e conflitos, em um processo dinâmico, vinculado à reprodução do capital. (SPOSITO, 2006).

$\mathrm{Na}$ perspectiva de que uma cidade pode atrair consumidores de cidades vizinhas, convém considerar que elas, muito frequentemente, situamse tão próximas umas das outras que, à medida que crescem e se relacionam mais e mais, sofrem uma importante transformação: os bens produzidos em uma cidade são vendidos na outra, ou os habitantes de uma cidade buscam determinados serviços especializados ligados a saúde e educação na outra, ou, ainda, de que instituições político-administrativas, legislativas, judiciárias, 
religiosas ou militares, sediadas em uma cidade, exerçam poder sobre a outra. (SOUZA, 2008).

O fluxo mais significativo desse processo é o de trabalhadores que residem em uma cidade e trabalham em outra, ou de estudantes que residem em uma cidade e estudam em outra. Esse fluxo denomina-se "deslocamento pendular", que significa a movimentação de pessoas do local de residência para o local de trabalho, retornando para o local de residência, ou então, do local de residência para o local de estudo, retornando para o local de residência. (SOUZA, 2008).

O deslocamento pendular de pessoas que residem em um município e se deslocam diariamente para outro, seja para trabalhar ou estudar, não se caracteriza como migração, pois não é realizado com o objetivo de mudança permanente ou por tempo indeterminado, e sim, devido à oportunidade de emprego, maior oferta de serviços de educação, saúde, transporte entre outros elementos que favorecem a consolidação desse fenômeno. (RABUSKE; BRANDT; SILVEIRA, 2015).

A utilização dos deslocamentos diários de trabalhadores ou estudantes permite agregar valor à "região", termo adotado no Brasil como um espaço de dimensões maiores, situado entre a escala nacional (o país) e a escala local (a cidade ou mesmo uma aglomeração de cidades ou uma metrópole). Kayser (1980, p. 23) sintetiza o conceito afirmando que "o espaço polarizado que se organiza em torno de uma cidade é uma região".

Neste estudo, considera-se região a escala local, portanto, uma aglomeração de cidades que se organizam, levando em conta suas particularidades, formando a totalidade, que é a região. Nessas condições, cidades e regiões não podem ser vistas desvinculadamente, pois cada estágio de desenvolvimento da produção da cidade corresponde a um estágio de desenvolvimento da produção espacial da região. O homem, nesse contexto, é um ser social agente da vida econômica e da produção do espaço. (CARLOS, 2000; LENCIONI, 2008).

Os laços entre as cidades e as regiões são resultado da construção histórica de ações articuladas de distintos processos sociais que expressam os interesses dos agentes e atores envolvidos. (LIMONAD, 2004). Essas ações podem ser traduzidas no deslocamento pendular de pessoas, tornando-se uma evidência incontestável da integração dos espaços "cidade-região" ou mesmo da ação das empresas e corporações. (ARRAIS, 2008).

O mesmo autor lembra que a ideia da integração dos espaços não é nova e foi motivada "[...] pelo reconhecimento de processos socioeconômicos que rompem os limites jurídico-administrativos do que convencionalmente chamamos de cidade". (ARRAIS, 2008, p. 82). Não se trata de hierarquizar escalas, mas de reconhecer que processos materializados por meio de diversos 
tipos de fluxo no espaço cidade-região são ações que influenciam a distribuição das pessoas e dos recursos, gerando o movimento pendular.

Identificar as diversas ações desenvolvidas pelas cidades, independente do número de habitantes, facilita a compreensão da sua história e de suas potencialidades, por meio da observação de suas capacidades e de seus vínculos sociais (FURINI, 2014) que, por sua vez, geram sentimento de pertencimento e identidade, tanto individual quanto coletivo, tanto à cidade quanto à região.

\section{A REDE URBANA E A CIDADE-REGIÃO}

A rede urbana, segundo Corrêa (1999), é entendida como um conjunto de centros articulados por meio de diversos agentes sociais no qual a produção, a circulação e o consumo se realizam. $O$ mesmo autor destaca que desta articulação emergem muitos tipos de redes urbanas, conforme combinações de características tais como: tamanho dos centros, densidade no espaço regional, funções que desempenham, natureza, intensidade, periodicidade e alcance espacial das interações e a forma da rede.

Nessas condições, a rede urbana está submetida a um dinamismo, próprio de cada contexto-temporal e/ou de cada formação espacial, que se origina tanto de variáveis externas a cada rede urbana, como de variáveis internas, a partir de possibilidades e motivações de seus agentes sociais. Como consequência desse dinamismo, as características das redes urbanas, citadas acima, podem sofrer alterações quanto ao tamanho, à densidade, as funções, à natureza e assim por diante. (CORRÊA, 2000).

O mesmo autor lembra que a globalização, por exemplo, afeta a rede urbana, seja por intermédio de criações urbanas recentes ou por refuncionalidade dos centros pré-existentes, imposta ou induzida pelas corporações globais. (CORRÊA, 1999). Assim, as cidades pequenas e médias, a partir dos anos 90, começam a viabilizar atividades diversas, com as condições de infraestrutura disponíveis, qualificação da mão de obra e boa qualidade de vida desses locais, muitas vezes menos urbanizados, mas também, menos congestionadas. (SOARES; FEDOZZI, 2010).

No processo de diferenciação, combinando funções centrais com as funções especializadas que adquiriu, a rede urbana busca novas interações, mais intensas e complexas, e de escalas local e regional, passando a interagir com as escalas nacional e internacional, evidenciando, assim, a capacidade e importância das pequenas e médias cidades enquanto formadoras de uma rede.

Isso quer dizer que a cidade-região, formada por centros urbanos menores e áreas rurais, constitui uma rede urbana. Essa concepção não faz distinção entre o urbano e o rural, pois compreende que as relações sociais, políticas e econômicas não estão separadas entre os espaços, ou seja, entre a cidade e o campo. 
Considerando a ideia de cidade-região, Arrais (2008) chama a atenção para a necessidade de se fomentar a discussão política em espaços integrados por uma rede urbana, na perspectiva da uma ação regional mais coesa. Configura-se, assim, questões como: a importância de considerar a relação entre o espaço e o modo de produção capitalista "[...] como uma via de mãodupla, como parte de uma relação dialética e complexa" (BOTELHO, 2007, p. 16); a necessidade de considerar as diferenças regionais/territoriais do planeta; o cuidado de não fomentar novas hierarquias sobre velhas hierarquias; e a necessidade de qualificar os atores sociais para pensar o regional. (ARRAIS, 2008).

As considerações descritas demonstram, portanto, a necessidade de entendimento da complexidade espacial atual. A adesão aos novos conceitos não pode ser movida apenas pela intuição, mas a partir da compreensão das particularidades das diversas regiões brasileiras e da valorização das redes urbanas interligadas, buscando a permanência nesse contexto global. Sobreposta a isso, a cidade-região insere a possibilidade de relações e complementaridade entre si, validando o que Santos (2009) defende como a "força do lugar" em um ambiente como o mundo de hoje.

\section{REGIÃO DO VALE DO TAQUARI-RS}

A região do Vale do Taquari, no estado do Rio Grande do Sul, é considerada fértil por suas riquezas ambientais e por apresentar ampla diversidade econômica. Composta por 36 municípios que totalizam $4.826,7 \mathrm{~km}^{2}$ (1,71\% do Estado) de área, é privilegiada por sua localização estratégica, estando a $117 \mathrm{~km}$ da capital, Porto Alegre, portanto, próxima da região metropolitana.

Em 2010, conforme o Censo Demográfico realizado pelo Instituto Brasileiro de Geografia e Estatística (IBGE), a região contava com 348.435 habitantes (3,11\% da população gaúcha), a grande maioria de origem alemã, italiana ou açoriana, embora antes da vinda do homem branco, viviam na região índios de várias origens. No mesmo ano, a densidade demográfica do Vale era de $68 \mathrm{hab} / \mathrm{km}^{2}$, enquanto o Estado atingia $37,96 \mathrm{hab} / \mathrm{km}^{2}$. (IBGE, 2010).

$\mathrm{O}$ nome Vale do Taquari deu-se em função do rio que a atravessa, o Taquari, cujo vocabulário indígena original era tebicuary, que significava "rio do barranco profundo". A cidade mais antiga da região tem o mesmo nome do rio (Taquari), e foi emancipada de Triunfo em 1849. Estrela e Lajeado já têm mais de 100 anos. A maioria dos municípios emancipou-se a partir de 1959. Os municípios mais populosos são, respectivamente, Lajeado, Estrela, Teutônia, Taquari, Encantado e Arroio do Meio, que respondem por 59,4\% do total da população regional.

Em 2012, o Produto Interno Bruto (PIB) da região superou $\mathrm{R} \$ 9,5$ bilhões ( $3,43 \%$ do PIB estadual). A indústria respondia por $27,54 \%$ desse total; o setor de serviços, por $46,03 \%$, e a agropecuária, por $16,04 \%$. No PIB per capita, o Vale 
chegou a $\mathrm{R} \$ 28.669,24$. Sua malha rodo-hidrográfica coloca o Vale do Taquari em posição favorável ao desenvolvimento socioeconômico. (IBGE, 2010).

A instalação de indústrias e o desenvolvimento do comércio e do setor de serviços provocaram mudanças significativas nos últimos 40 anos. Em $1970,74,27 \%$ da população viviam no meio rural e, passadas quatro décadas, o quadro praticamente se inverteu: em $2010,73,84 \%$ viviam na zona urbana. Nos municípios pequenos, destaca-se o setor da agropecuária, enquanto nos municípios maiores sobressaem-se atividades ligadas à indústria e ao setor de serviços e comércio. (PREFEITURA ..., 2017, texto digital).

\section{UNIVERSIDADE DO VALE DO TAQUARI - UNIVATES}

O planejamento de instalação do ensino superior em Lajeado foi iniciado pela Associação Pró-Ensino Universitário do Alto Taquari (APEUAT), fundada em 23 de março de 1964. Já a autorização do Ministério da Educação e Cultura (MEC) para a criação do ensino superior em Lajeado ocorreu em 31 de dezembro de 1968 e, por meio da extensão da Universidade de Caxias do Sul (UCS), em 17 de janeiro de 1969, foram ofertados os primeiros cursos.

$\mathrm{Na}$ época, os cursos oferecidos eram Letras - Licenciatura Plena, Ciências Econômicas e Ciências Contábeis. Na sequência, em 1972, a instituição deixa de ser uma extensão da UCS e passa a atuar de forma independente, com a transformação da APEUAT em Fundação Alto Taquari de Ensino Superior (FATES) obtendo, respectivamente, em 1974 e em 1975, o reconhecimento da Faculdade de Letras do Alto Taquari (FELAT) e da Faculdade de Ciências Econômicas do Alto Taquari (FACEAT) pelo Ministério da Educação e Cultura (MEC).

Em 1997, ocorre a fusão das faculdades FELAT e FACEAT, passando a denominar-se Univates, sendo credenciada, em $1^{\circ}$ de julho de 1999, como Centro Universitário Univates, mantido pela Fundação Vale do Taquari de Educação e Desenvolvimento Social (FUVATES), que substituiu a Fates em 16 de agosto de 2000.

Com isso, o Centro Universitário Univates traçou metas e estratégias objetivando gerar e disseminar conhecimentos para atender as necessidades locais e as tendências mundiais, obtendo muitas conquistas, entre elas a abertura do primeiro curso de mestrado em Ambiente e Desenvolvimento (2006), a inauguração do Complexo Esportivo, em 2007, considerado o maior dos Vales do Taquari e Rio Pardo, vários cursos avaliados como os melhores do Brasil, segundo o Exame Nacional de Desempenho de Estudantes (ENADE) e, em 2011, a instalação do primeiro curso de doutorado, em Ambiente e Desenvolvimento.

Em 2013, a Instituição é autorizada a ofertar o curso de Medicina. Em 2014, várias conquistas ocorrem, como: inauguração do Centro Cultural Univates, que abriga a biblioteca, com um acervo total de 64.972 obras e 159.891 
volumes; teatro para 1.150 pessoas, salas especiais e área de lazer; inauguração do Parque Científico e Tecnológico da Univates - Tecnovates, um espaço destinado ao desenvolvimento do conhecimento, da ciência e da tecnologia; e inauguração do Estádio Olímpico.

A exemplo de anos anteriores, 2015 foi de realizações, sendo a maior a inauguração do Ambulatório de Especialidades Médicas no Centro Clínico Univates, espaço que abriga a integração entre o ensino, o serviço e a comunidade, destinado à prestação de serviços multiprofissionais em atenção integral à saúde, articulando as atividades de ensino, pesquisa e extensão.

No dia 26 de julho de 2017, o Vale do Taquari, que há 50 anos uniu forças para trazer o ensino superior à região, visando a qualificar e desenvolver pessoas, colhe um fruto importante de seu trabalho coletivo: a Univates recebe a concessão do título de Universidade do Vale do Taquari - Univates.

Os integrantes da reitoria trabalham para atender o princípio da pluralidade, que visa à unidade sem prejuízo da individualidade do ser humano, com a missão de promover conhecimentos, atendendo necessidades da realidade regional, inseridas no contexto universal, com permanente olhar para o equilíbrio da qualidade de vida.

O campus sede da Univates está localizado no Bairro Universitário, em Lajeado. Atualmente, a Instituição conta com 25 prédios que comportam setores administrativos, salas de aulas, auditórios, laboratórios, cafeteria, biblioteca, cozinhas, centros tecnológicos, Unianálises, Inovates, gabinetes docentes, centro de conveniência, oficina de manutenção, piscinas, arena, ginástica olímpica e sede social.

\section{RESULTADOS DA PESQUISA}

Esta pesquisa não tem a pretensão de analisar e/ou destacar a Universidade do Vale do Taquari - Univates a partir de uma visão competitiva, e sim de identificar o deslocamento pendular para estudo, promovido por ela. A universidade, no segundo semestre de 2017, contabiliza 8.033 estudantes na graduação, 501 na pós-graduação lato sensu e 1.734 em educação profissional (cursos técnicos).

No mesmo período, conta com 47 cursos de graduação, 31 cursos de pós-graduação lato sensu e 17 cursos de educação profissional, além de vários cursos de educação continuada, projetos de extensão e projetos de pesquisa (UNIVERSIDADE...., Intranet/Planejamento e Avaliação Institucional, 2017, texto digital).

A Tabela 1 apresenta o deslocamento pendular para estudo, por cidade da região do Vale do Taquari-RS, a partir das pessoas matriculadas na Universidade do Vale do Taquari - Univates, no segundo semestre de 
2017. Estão sendo identificados três níveis de cursos: educação profissional' ${ }^{3}$, graduação e pós-graduação lato sensu.

Embora o município de Lajeado, neste trabalho, não se caracteriza como deslocamento pendular diário para estudo, a mesma consta nas Tabelas 1 e 2 com a finalidade de identificar quantas pessoas frequentam a Univates, nessa mesma cidade.

Observa-se, por meio da Tabela 1, que os municípios de Teutônia, Estrela, Arroio do Meio e Encantado são os que apresentam o maior número de pessoas que se deslocam diariamente para Lajeado por motivo de estudo, no ensino superior. O município de Teutônia destaca-se com 878 pessoas, representando $10,22 \%$ do total de matriculados; Estrela, com 856 pessoas, representa 9,97\% do total de matriculados; Arroio do Meio, com 649 pessoas, equivale a 7,56\% dos matriculados; e Encantado, com 605 pessoas, equivale a 7,04\% dos matriculados que se deslocam para estudar no município de Lajeado, na Universidade do Vale do Taquari - Univates.

Tabela 1 - Deslocamento pendular - por cidade de procedência da região do Vale do Taquari

\begin{tabular}{lccccc}
\hline \multicolumn{5}{c}{$\begin{array}{c}\text { Número de pessoas matriculadas e de cidades de procedência da região do Vale do Taquari-RS que se } \\
\text { deslocam para fins de estudo, no segundo semestre de }\end{array}$} \\
\hline \multicolumn{1}{c}{ Cidade } & Educação Profissional & Graduação & Pós-Graduação & Total & Percentual \\
\hline Lajeado & 455 & 2329 & 231 & 3015 & $35,10 \%$ \\
Teutônia & 132 & 696 & 50 & 878 & $10,22 \%$ \\
Estrela & 119 & 676 & 61 & 856 & $9,97 \%$ \\
Arroio do Meio & 123 & 485 & 41 & 649 & $7,56 \%$ \\
Encantado & 85 & 494 & 26 & 605 & $7,04 \%$ \\
Taquari & 51 & 222 & 10 & 283 & $3,29 \%$ \\
Cruzeiro do Sul & 40 & 202 & 12 & 254 & $2,96 \%$ \\
Bom Retiro do Sul & 68 & 154 & 6 & 228 & $2,65 \%$ \\
Roca Sales & 34 & 151 & 16 & 201 & $2,34 \%$ \\
Anta Gorda & 28 & 96 & 5 & 129 & $1,50 \%$ \\
Muçum & 22 & 104 & 3 & 129 & $1,50 \%$ \\
Santa Clara do Sul & 27 & 83 & 5 & 115 & $1,34 \%$ \\
Nova Bréscia & 18 & 72 & 5 & 95 & $1,11 \%$ \\
Progresso & 25 & 62 & 5 & 92 & $1,07 \%$ \\
Paverama & 25 & 60 & 5 & 90 & $1,05 \%$ \\
Westfália & 14 & 70 & 1 & 85 & $0,99 \%$ \\
Imigrante & 20 & 46 & 7 & 73 & $0,85 \%$ \\
Marques de Souza & 10 & 66 & 0 & 70 & $0,81 \%$ \\
Arvorezinha & 7 & 52 & 5 & 64 & $0,75 \%$
\end{tabular}

3 Os cursos de Educação Profissional compreendem o conjunto de atividades que visam a aquisição teórica e/ou prática de conhecimentos, habilidades e atitudes exigidos para o exercício de uma profissão. Assim, a formação profissional apresenta-se como um instrumento que propicia qualificação e aperfeiçoamento profissional contínuo. 


\begin{tabular}{lccccc}
\hline \multicolumn{5}{c}{$\begin{array}{c}\text { Número de pessoas matriculadas e de cidades de procedência da região do Vale do Taquari-RS que se } \\
\text { deslocam para fins de estudo, no segundo semestre de 2017, em três níveis de cursos }\end{array}$} \\
\hline \multicolumn{1}{c}{ Cidade } & Educação Profissional & Graduação & Pós-Graduação & Total & Percentual \\
\hline Colinas & 8 & 41 & 10 & 59 & $0,69 \%$ \\
Dois Lajeados & 13 & 43 & 1 & 57 & $0,66 \%$ \\
Poço das Antas & 7 & 49 & 0 & 56 & $0,65 \%$ \\
Ilópolis & 6 & 46 & 1 & 53 & $0,62 \%$ \\
Tabaí & 12 & 39 & 1 & 52 & $0,61 \%$ \\
Fazenda Vilanova & 17 & 32 & 2 & 51 & $0,59 \%$ \\
Putinga & 13 & 35 & 0 & 48 & $0,56 \%$ \\
Capitão & 16 & 29 & 1 & 46 & $0,54 \%$ \\
Travesseiro & 14 & 30 & 2 & 46 & $0,54 \%$ \\
Doutor Ricardo & 10 & 29 & 0 & 39 & $0,45 \%$ \\
Forquetinha & 6 & 22 & 0 & 28 & $0,33 \%$ \\
Pouso Novo & 7 & 20 & 0 & 27 & $0,31 \%$ \\
Vespasiano Corrêa & 6 & 21 & 0 & 27 & $0,31 \%$ \\
Relvado & 6 & 18 & 1 & 25 & $0,29 \%$ \\
Coqueiro Baixo & 10 & 13 & 1 & 24 & $0,28 \%$ \\
Sério & 4 & 17 & 1 & 22 & $0,26 \%$ \\
Canudos Do Vale & 2 & 17 & 0 & 19 & $0,22 \%$ \\
\hline TOTAL & $\mathbf{1 4 6 0}$ & $\mathbf{6 6 1 5}$ & $\mathbf{5 1 5}$ & $\mathbf{8 5 9 0}$ & $\mathbf{1 0 0} \%$ \\
\hline
\end{tabular}

Fonte: Elaborado pelos autores, com dados da Univates/Intranet, Planejamento e Avaliação Institucional (2017).

Além dos quatro municípios com maior representatividade de pessoas que se deslocam diariamente para estudo, de outros 31 municípios também procedem pessoas que se deslocam pelo mesmo motivo, em pelo menos dois dos três níveis de cursos superiores oferecidos. Diante disso, tem-se um deslocamento pendular diário de pessoas de 35 municípios dos 36 que compõem a região do Vale do Taquari-RS (Lajeado não está sendo considerado na análise).

A Tabela 2 apresenta o deslocamento pendular para estudo de todas as cidades e dos três níveis de cursos, a partir das pessoas matriculadas na Universidade do Vale do Taquari - Univates, no segundo semestre de 2017. Os níveis de cursos são: educação profissional, graduação e pós-graduação lato sensu. 
Tabela 2 - Deslocamento pendular- por todas as cidade de procedência e nível de curso

\begin{tabular}{|c|c|c|c|c|c|}
\hline \multicolumn{6}{|c|}{$\begin{array}{l}\text { Número de pessoas e de cidades de procedência presentes na universidade, no segundo semestre de } \\
2017 \text {, em três níveis de cursos }\end{array}$} \\
\hline Cidade & Educação Profissional & Graduação & Pós-Graduação & Total & Percentual \\
\hline Lajeado & 455 & 2329 & 231 & 3015 & $28,71 \%$ \\
\hline Teutônia & 132 & 696 & 50 & 878 & $8,36 \%$ \\
\hline Estrela & 119 & 676 & 61 & 856 & $8,15 \%$ \\
\hline Arroio do Meio & 123 & 485 & 41 & 649 & $6,18 \%$ \\
\hline Encantado & 85 & 494 & 26 & 605 & $5,76 \%$ \\
\hline Venâncio Aires & 90 & 448 & 23 & 561 & $5,34 \%$ \\
\hline Guaporé & 64 & 273 & 10 & 347 & $3,30 \%$ \\
\hline Taquari & 51 & 222 & 10 & 283 & $2,69 \%$ \\
\hline Cruzeiro do Sul & 40 & 202 & 12 & 254 & $2,42 \%$ \\
\hline Bom Retiro do Sul & 68 & 154 & 6 & 228 & $2,17 \%$ \\
\hline Roca Sales & 34 & 151 & 16 & 201 & $1,91 \%$ \\
\hline Anta Gorda & 28 & 96 & 5 & 129 & $1,23 \%$ \\
\hline Muçum & 22 & 104 & 3 & 129 & $1,23 \%$ \\
\hline Carlos Barbosa & 14 & 105 & 4 & 123 & $1,17 \%$ \\
\hline Santa Clara do Sul & 27 & 83 & 5 & 115 & $1,09 \%$ \\
\hline Garibaldi & 5 & 87 & 3 & 95 & $0,90 \%$ \\
\hline Nova Bréscia & 18 & 72 & 5 & 95 & $0,90 \%$ \\
\hline Progresso & 25 & 62 & 5 & 92 & $0,88 \%$ \\
\hline Paverama & 25 & 60 & 5 & 90 & $0,86 \%$ \\
\hline Mato Leitão & 23 & 59 & 3 & 85 & $0,81 \%$ \\
\hline Westfália & 14 & 70 & 1 & 85 & $0,81 \%$ \\
\hline Boqueirão do Leão & 14 & 60 & 2 & 76 & $0,72 \%$ \\
\hline Imigrante & 20 & 46 & 7 & 73 & $0,70 \%$ \\
\hline Santa Cruz do Sul & 3 & 46 & 23 & 72 & $0,69 \%$ \\
\hline Marques de Souza & 10 & 60 & 0 & 70 & $0,67 \%$ \\
\hline Arvorezinha & 7 & 52 & 5 & 64 & $0,61 \%$ \\
\hline Colinas & 8 & 41 & 10 & 59 & $0,56 \%$ \\
\hline Dois Lajeados & 13 & 43 & 1 & 57 & $0,54 \%$ \\
\hline Poço das Antas & 7 & 49 & 0 & 56 & $0,53 \%$ \\
\hline Serafina Corrêa & 10 & 42 & 3 & 55 & $0,52 \%$ \\
\hline Ilópolis & 6 & 46 & 1 & 53 & $0,50 \%$ \\
\hline Tabaí & 12 & 39 & 1 & 52 & $0,50 \%$ \\
\hline Fazenda Vilanova & 17 & 32 & 2 & 51 & $0,49 \%$ \\
\hline Putinga & 13 & 35 & 0 & 48 & $0,46 \%$ \\
\hline Boa Vista do Sul & 14 & 32 & 0 & 46 & $0,44 \%$ \\
\hline Capitão & 16 & 29 & 1 & 46 & $0,44 \%$ \\
\hline Travesseiro & 14 & 30 & 2 & 46 & $0,44 \%$ \\
\hline Fontoura Xavier & 15 & 30 & 0 & 45 & $0,43 \%$ \\
\hline Doutor Ricardo & 10 & 29 & 0 & 39 & $0,37 \%$ \\
\hline São José do Herval & 11 & 17 & 1 & 29 & $0,28 \%$ \\
\hline Forquetinha & 6 & 22 & 0 & 28 & $0,27 \%$ \\
\hline Porto Alegre* & 0 & 23 & 5 & 28 & $0,27 \%$ \\
\hline Pouso Novo & 7 & 20 & 0 & 27 & $0,26 \%$ \\
\hline Vespasiano Corrêa & 6 & 21 & 0 & 27 & $0,26 \%$ \\
\hline
\end{tabular}




\begin{tabular}{|c|c|c|c|c|c|}
\hline \multicolumn{6}{|c|}{$\begin{array}{l}\text { Número de pessoas e de cidades de procedência presentes na universidade, no segundo semestre de } \\
2017 \text {, em três níveis de cursos }\end{array}$} \\
\hline Cidade & Educação Profissional & Graduação & Pós-Graduação & Total & Percentual \\
\hline Relvado & 6 & 18 & 1 & 25 & $0,24 \%$ \\
\hline Bento Gonçalves & 0 & 22 & 2 & 24 & $0,23 \%$ \\
\hline Coqueiro Baixo & 10 & 13 & 1 & 24 & $0,23 \%$ \\
\hline Sério & 4 & 17 & 1 & 22 & $0,21 \%$ \\
\hline Canudos do Vale & 2 & 17 & 0 & 19 & $0,18 \%$ \\
\hline Santa Maria** & 0 & 8 & 5 & 13 & $0,12 \%$ \\
\hline Triunfo & 3 & 9 & 0 & 12 & $0,11 \%$ \\
\hline Outras cidades ${ }^{* * *}$ & 8 & 157 & 137 & 302 & $2,88 \%$ \\
\hline TOTAL & 1734 & 8033 & 736 & 10503 & $100 \%$ \\
\hline
\end{tabular}

Fonte: Elaborado pelos autores, com dados da Univates/Intranet, Planejamento e Avaliação Institucional (2017).

A Tabela 2 ilustra o número de pessoas e de cidades presentes na universidade, no segundo semestre de 2017, em três níveis de cursos. Além dos quatro municípios da região do Vale do Taquari (Teutônia, Estrela, Arroio do Meio e Encantado) com maior representatividade de pessoas que se deslocam diariamente para estudar na Univates, em Lajeado, mencionados na Tabela 1, é possível afirmar que muitos outros muitos municípios também se deslocam pessoas para estudar em pelo menos dois dos três níveis de cursos oferecidos pela mesma universidade.

Reitera-se que Lajeado não está sendo considerada nessa análise, assim como os estudantes de Porto Alegre e de Santa Maria que cursam graduação e ficam em Lajeado de segunda a sexta-feira. Estima-se, também, que muitas das pessoas das outras 202 cidades de fora da região do Vale do Taquari e, algumas, de fora do estado do Rio Grande do Sul, se utilizam da mesma logística, ou seja, permanecem por tempo indeterminado em Lajeado.

Mesmo excluindo os números percentuais relativos a essas particularidades, pode-se afirmar que o deslocamento pendular provocado pela Universidade do Vale do Taquari - Univates é bastante representativo, uma vez que mais de $60 \%$ do total de pessoas matriculadas no segundo semestre de 2017 se deslocam diariamente para estudar em Lajeado-RS.

Cabe ressaltar que os resultados deste estudo referem-se exclusivamente ao deslocamento pendular de estudantes promovido pela Universidade do Vale do Taquari - Univates, mas acredita-se que esse tema, devido à sua extensão, não se esgota em um único trabalho, sugerindo outros que possam mensurar e quantificar de forma detalhada tais movimentações, inclusive com a utilização de outras metodologias. Assim, ficam sugestões para futuros estudos, em um contínuo processo de pesquisa e geração de novos conhecimentos. 


\section{CONSIDERAÇÕES FINAIS}

As cidades formam uma rede urbana por meio de pessoas, produção, mercadorias, informações e objetivos que caracterizam os fixos e fluxos de cada cidade e da região, bem como os laços entre elas, fruto de ações articuladas de diversos agentes, atores sociais e organizações.

Essas ações podem ser traduzidas no grande movimento pendular de pessoas que se deslocam até a Universidade do Vale do Taquari - Univates para estudar, conforme dados identificados. Esses mesmos dados ainda revelam a inserção da universidade nos contextos regional, nacional e global e o seu papel enquanto promotora de conhecimento técnico-científico e humanístico, expandindo continuamente qualidade de vida.

Nessa perspectiva, é possível afirmar que a Universidade do Vale do Taquari - Univates, ao atrair estudantes e promover deslocamento pendular, também está contribuindo para a desconcentração metropolitana, com vistas, quem sabe, à democratização "no" e "do" espaço, potencializando a reprodução do capital e da qualidade de vida em mais cidades, em mais regiões.

Por fim, embora não tenha sido objetivo do estudo analisar quais são os motivos que levam as pessoas a se deslocarem diariamente para a Universidade do Vale do Taquari - Univates, arrisca-se apresentar hipóteses para a ocorrência desse fenômeno, tais como: a variedade de cursos oferecidos, a infraestrutura existente, a qualidade de ensino, a localização geográfica e a facilidade de transporte.

A pesquisa evidencia que muitas vidas se entrelaçam com a universidade e a cidade de Lajeado, demonstrando suas contribuições no contexto regional e global, especialmente se considerarmos o conceito de rede urbana. Sem dúvida, o grau de interação e importância de cada cidade da região do Vale do Taquari é um indicativo de seu nível de desenvolvimento, refletido na força das suas relações e na sua capacidade de aproximar, sonhar e realizar.

\section{Referências}

ARRAIS, Tadeu Alencar. A cidade e a região/a cidade-região: reconhecer processos, construir políticas. Disponível em: <https://revistas.pucsp.br/index.php/metropole/ article/view/8637/6424>. Acesso em: 25 ago. 2017.

ASSEMBLÉIA LEGISLATIVA DO ESTADO DO RIO GRANDE DO SUL. Porto Alegre, 2008. Disponível em: <http://www.al.rs.gov.br/filerepository/repLegis/ arquivos/DEC\%2045.436.pdf>. Acesso em: 03 set. 2017.

BOTELHO, Adriano. A cidade como negócio: produção do espaço e acumulação do capital no município de São Paulo. In: Cadernos Metrópole, [S.l.], n. 18, p. 15-38, 2007. Disponível em: <https:/ / revistas.pucsp.br/index.php/metropole/article/ view/8727>. Acesso em: 07 set. 2017. 
CARLOS, Ana Fani Alessandri. A cidade. 9. ed. São Paulo: Contexto, 2011.

CORREAA, Roberto Lobato. Região e organização espacial. São Paulo: Ática, 2000.

. Globalização e reestruturação da rede urbana - uma nota sobre as pequenas cidades. Revista Território, [S.1.], ano IV, n. 6, jan./jun. 1999.

FLORES, Murilo. A identidade cultural do território como base de estratégias de desenvolvimento: uma visão do estado da arte. [S.1.], 2006. Disponível em: <https:/ / pt.scribd.com/document/135006291/FLORES-M-a-Identidade-Cultural>. Acesso em: 09 out. 2017.

FURINI, Luciano Antonio. Os agentes urbanos: conceito e características principais. Revista Geografia e Pesquisa, Ourinhos, v. 8, n. 1, p. 15-24, 2014. Disponível em: $<$ http:/ / scholar.google.com.br/citations?user=GrcalMMAAAAJ\&hl=pt-BR>. Acesso em: 08 out. 2017.

IBGE CIDADES. Censo Demográfico de 2010. Disponível em: <https:/ / cidades.ibge. gov.br/brasil/rs/porto-alegre/panorama>. Acesso em: 09 out. 2017.

KAYSER, Bernard. A região como objeto de estudo da geografia. In: GEORGE, Pierre et al. A geografia ativa. São Paulo: Difel, 1980. p. 279-321.

LENCIONI, Sandra. Observações sobre o conceito de cidade e urbano. In: GEOUSP - Espaço e Tempo, São Paulo, n. 24, p. 109-123, 2008. Disponível em: <http:/ /www. revistas.usp.br/geousp/article/view/74098/77740>. Acesso em: 07 set. 2017.

PREFEITURA MUNICIPAL DE LAJEADO. Lajeado, 2017. Disponível em: <http:/ / www.lajeado.rs.gov.br $/$ titulo $=$ Lajeado\&template $=$ conteudo\&categoria $=931 \&$ codigoCategoria $=931 \& i d C o n t e u d o=2952 \&$ tipoConteudo=INCLUDE_MOSTRA_CONTEUDO>. Acesso em: 10 out. 2017.

RABUSKE, Ana Cristina; BRANDT, Grazielle Betina; SILVEIRA, Rogério Leandro Lima da. Observando as migrações e deslocamentos na região do Vale do Rio Pardo/ RS. Revista Jovens Pesquisadores, Santa Cruz do Sul, v. 5, n. 1, p. 118-133, 2015. Disponível em: <https://online.unisc.br/seer/index.php/jovenspesquisadores / article/view/5727>. Acesso em: 08 out. 2017.

SANTOS, Milton. A natureza do espaço: técnica e tempo. Razão e Emoção. São Paulo: Editora da Universidade de São Paulo, 2009.

SOARES, Paulo Roberto Rodrigues; FEDOZZI, Luciano Joel. Porto Alegre e sua região metropolitana no contexto das contradições da metropolização brasileira contemporânea. Sociologias, Porto Alegre, ano 18, n. 42, mai./ago, p. 162-197, 2016. Disponível em: <http:/ / www.scielo.br/pdf/soc/v18n42/1517-4522-soc-18-42-00162. pdf $>$. Acesso em: 20 set. 2017.

SOUZA, Marcelo Lopes de. ABC do desenvolvimento urbano. 4. ed. Rio de Janeiro: Bertrand Brasil, 2008. 
SPOSITO, Maria Encarnação Beltrão. A questão cidade-campo: perspectivas a partir da cidade. In: SPOSITO, Maria E. B. (Org.). Cidade e campo: relações e contradições entre urbano e rural. São Paulo: Editora Expressão Popular, 2006. p. 111-130.

UNIVERSIDADE DO VALE DO TAQUARI - UNIVATES. Institucional. Lajeado, RS, 2017. Disponível em: <http:/ / www.univates.br/institucional >. Acesso em: 08 out. 2017.

UNIVERSIDADE DO VALE DO TAQUARI - UNIVATES. Intranet. Planejamento e Avaliação Institucional. Lajeado, RS, 2017. Disponível em: <https:/ / www.univates. br/intranet/setores/planejamento>. Acesso em: 08 out. 2017. 